\title{
Changes in blood eosinophilia during omalizumab therapy as a predictor of asthma exacerbation
}

\author{
Roman Skiepko', Ziemowit Ziętkowski ${ }^{1}$, Mateusz Łukaszyk ${ }^{1}$, Wojciech Budny¹, Urszula Skiepko', Robert Milewski², \\ Anna Bodzenta-tukaszyk ${ }^{1}$
}

\author{
'Department of Allergology and Internal Medicine, Medical University of Bialystok, Bialystok, Poland \\ Head of Department: Prof. Anna Bodzenta-Lukaszyk MD, PhD \\ 2Department of Statistics and Medical Informatics, Medical University of Bialystok, Bialystok, Poland \\ Head of Department: Prof. Tomasz Burzykowski
}

Postep Derm Alergol 2014; XXXI, 5: 305-309

DOI: $10.5114 / p d i a .2014 .40973$

\begin{abstract}
Introduction: Omalizumab is a monoclonal anti-immunoglobulin E antibody developed for the treatment of severe allergic asthma. The number of exacerbations used as a parameter of omalizumab therapy efficacy may be insufficient in many cases due to a relatively short time to first evaluation (16 weeks). Therefore, it is advisable to look for parameters of more prognostic value while continuing omalizumab therapy.

Aim: To evaluate usefulness of analysis of changes of blood eosinophilia after 16 weeks of omalizumab therapy as a predictor of asthma exacerbations.

Material and methods: The study was conducted on a group of 13 patients with severe persistent allergic asthma treated with omalizumab. Blood eosinophil counts were measured before and after 16 weeks of anti-lgE therapy. On the basis of percentage of eosinophilia decrease ( $>50 \%$ or $<50 \%$ of the initial value), patients were divided into two groups. Analysis of the asthma exacerbation rate during 12 months and time to first exacerbation was performed. Results: In the group with a high decrease in blood eosinophil counts (group 1) we showed a statistically significantly lower asthma exacerbation rate in 12 months compared with the group with a low decrease in blood eosinophil counts (group 2) $(p=0.02)$. We also observed the tendency to longer time to first asthma exacerbation in group 1 compared to group $2(p=0.06)$.

Conclusions: Our results showed that a decrease in blood eosinophilia during omalizumab therapy can be a predictor of asthma exacerbation. Evaluation of changes in blood eosinophil count should be taken into the consideration while estimating response to anti-lgE therapy in patients with severe allergic asthma.
\end{abstract}

Key words: omalizumab, eosinophils, asthma exacerbation.

\section{Introduction}

Omalizumab is a monoclonal anti-immunoglobulin E antibody developed for the treatment of asthmatic patients with inadequately controlled severe persistent allergic asthma despite optimal controller therapy [1]. Binding of IgE to high-affinity ( $F(\varepsilon R I)$ or low-affinity receptors (FcERII) on several cell types, and subsequent exposure to an allergen, initiates an inflammatory cascade resulting in induction of cell activation and the release of inflammatory mediators, which contribute to acute and chronic symptoms of asthma [2, 3]. These actions reduce IgE-mediated response to allergens and release of pro-inflammatory mediators [4-6]. Moreover, omalizum- ab reduced the late asthmatic response, which has been shown to be associated with inflammatory cell influx into the airways [7].

The clinical efficacy of omalizumab in severe persistent allergic asthma was described in clinical trials [8-11] and real-life studies in which omalizumab was used as an add-on therapy as it reduced the number of asthma exacerbations, use of corticosteroids and rescue medications [12-14].

There are many forms and parameters we use for evaluating omalizumab efficacy: Asthma Control Test, pulmonary function tests, unscheduled healthcare utilization, asthma symptoms, asthma exacerbations and systemic corticosteroids use. The number of exacerba-

Address for correspondence: Roman Skiepko MD, PhD, Department of Allergology and Internal Medicine, Medical University of Bialystok, 24 A Sklodowska-Curie St, 15-276 Bialystok, Poland, phone: +48 8574683 73, fax: +48 8574686 01, e-mail: roman_skiepko@op.pl Received: 10.01.2014, accepted: 11.04.2014. 
tions used as a parameter of omalizumab therapy efficacy may be insufficient in many cases due to a relatively short time to first evaluation (16 weeks). Therefore, it is advisable to look for parameters of more prognostic value while continuing omalizumab therapy.

Eosinophils play a significant role among many cells involved in pathogenesis of allergic inflammation in asthma. Eosinophils have long been implicated in asthma pathogenesis by way of releasing many mediators and oxygen reactive agents that damage epithelial cells and enhance neural responses [15]. They are also a source of cysteinyl leukotrienes that exert potent effects on bronchial smooth muscle, blood vessels, and mucosal glands. The peripheral blood eosinophil counts is a well-recognized marker of inflammation in asthma [16]. Sputum eosinophilia is a typical feature of asthma that broadly correlates with asthma severity and is associated with a greater risk of exacerbation [17].

There is evidence that blocking IgE with omalizumab has an inhibitory effect on eosinophils. Djukanović et al. reported that omalizumab significantly reduced the number of sputum and bronchial submucosal eosinophils in patients with allergic asthma [5]. Overall, these clinical data suggest that omalizumab is able to modulate eosinophil counts in blood as well as in sputum and within the lung.

\section{Aim}

The aim of the study was to evaluate usefulness of analysis of changes of blood eosinophilia after 16 weeks of omalizumab therapy as a predictor of asthma exacerbations.

\section{Material and methods \\ Patients}

The study was conducted on a group of 13 patients with severe persistent allergic asthma. All patients were treated with regular therapy according to step 4 criteria recommended by GINA 2006 [18]. They had been taking constant, high doses of inhaled corticosteroids (ICS) and long-acting $\beta_{2}$-agonists for at least 6 months. All the patients were atopic and sensitized to common inhaled allergens, as evaluated by skin prick tests; they had total serum IgE of at least $30 \mathrm{lU} / \mathrm{ml}$ to no more than $700 \mathrm{IU} /$ $\mathrm{ml}$. They were non-smokers and during the last year had not been passive smokers. All patients were routinely assessed to exclude alternative diagnoses, which may mimic severe allergic asthma.

Patients were treated with omalizumab on the basis of the concentration of serum total IgE and patient body weight at baseline [19].

Data were collected from hospital medical records between Dec 2007 and Jan 2013. Data collected included patient demographics, documented exacerbations, omalizumab dosing, blood eosinophil counts, concentration of exhaled nitric oxide $\left(F_{E N O}\right)$, forced exhalation volume in $1^{\text {st }} \mathrm{S}\left(\mathrm{FEV}_{1}\right)$. All measurements were performed before and after 16 weeks and 12 months of omalizumab treatment.

Asthma exacerbations have been defined as a worsening of asthma requiring treatment with oral or intravenous corticosteroids and/or doubling of baseline ISC dose for 3 or more days.

After 16 weeks of omalizumab treatment, on the basis of GETE (Global Evaluation of Treatment Effectiveness) scale, 4 patients were excluded from anti-lgE therapy (non-responders group). Patients with an excellent or good effect of treatment in GETE scale continued treatment. On the basis of serum eosinophil count reduction compared to baseline, we divided patients into two groups: with (group 1) and without (group 2) reduction of more than $50 \%$.

The study protocol was approved by the Ethics of Research Committee of the Medical University of Bialystok, agreement number: R-I-002/68/2007, R-I-002/301/2013. Informed consent was obtained from every patient and healthy volunteer enrolled into the study.

\section{Measurements}

Exhaled nitric oxide $\left(\mathrm{F}_{\mathrm{ENO}}\right)$ was measured in all patients by the chemiluminescence technique, using a Sievers 280i NO Analyzer (Boulder, Colorado, USA). The measurements were performed at an expiratory flow of $50 \mathrm{ml} / \mathrm{s}$ [20]. The duration of exhalation had to be at least $6 \mathrm{~s}$ to produce a stable NO level for $3 \mathrm{~s}$. All subjects had three recorded $F_{E N O}$ measurements. Repeated measurements were performed until the 3 values agreed within $10 \%$ of the mean. The mean value of the three measurements was recorded as the final $F_{E N O}$ level.

The baseline spirometry was performed using a MasterScreen Pneumo PC spirometer (Jaeger, Hoechberg, Germany). Spirometry was performed according to ATS standards [21]. Forced expiratory volume in $1^{\text {st }} \mathrm{s}$ was evaluated. Before the examination the patients did not take any medications that could change spirometry results. The highest value from three technically satisfactory attempts was attached.

Serum total IgE concentrations were measured using ImmunoCAP'M Technology (Pharmacia Diagnostics, Uppsala, Sweden).

Blood eosinophil count was measured using a hematologic analyzer (Coulter Electronics GmbH, Miami, Florida, USA).

\section{Statistical analysis}

In statistical analysis, non-normal distributions have been found. To compare non-parametric data between two groups Mann-Whitney test was used. Probability $(p)$ value was considered significant when it was 0.05 or less. All statistical analyses were performed using the Statistica 10.0 (StatSoft). 
Table 1. Baseline demographic and clinical characteristics

\begin{tabular}{lccc}
\hline Characteristics & Group 1 & Group 2 & $\begin{array}{c}\text { Differences between } \\
\text { groups, } p \text {-value }\end{array}$ \\
\hline Number of patients & 7 & 6 & \\
\hline Gender [F/M] & $5 / 2$ & $6 / 0$ & 0.36 \\
\hline Age [years] & $52.0 \pm 8.6$ & $49.3 \pm 8.2$ & 0.13 \\
\hline Duration of asthma [years] & $36 \pm 2.7$ & $30.0 \pm 10.7$ & 0.73 \\
\hline Baseline FEV ${ }_{1}[\%$ predicted] & $42.0 \pm 9.8$ & $44.0 \pm 27.5$ & 0.003 \\
\hline Blood eosinophil counts [cells/mm 3 ] & $375 \pm 242.9$ & $100 \pm 88.9$ & 0.94 \\
\hline Serum total lgE [kU/l] & $319 \pm 181$ & $192 \pm 608$ & 0.17 \\
\hline Baseline $\mathrm{F}_{\text {ENo }}[\mathrm{ppB}]$ & $94.0 \pm 49.8$ & $24.5 \pm 52.1$ & 0.83 \\
\hline ICS $^{1}[\mu \mathrm{g} /$ day] & $1000 \pm 433$ & $1125 \pm 540$ & \\
\hline
\end{tabular}

Data are presented as medians. ${ }^{1} / n h a l e d$ corticosteroids (fluticasone propionate equivalent).

\section{Results}

The characteristics of patients are presented in Table 1.

In the group with a high decrease in blood eosinophil count (group 1) we showed a statistically significantly lower asthma exacerbation rate in 12 months compared to the group with a low decrease in blood eosinophil counts ( $p=0.02$ ) (Figure 1). We also observed the tendency to longer time to first asthma exacerbation in group 1 compared to group $2(p=0.06)$ (Figure 2 ).

In group 1, blood eosinophil counts were statistically higher than in group $2(p=0.003)$ (Figure 3).

\section{Discussion}

Prevention of exacerbation is one of the main goals of asthma treatment [18]. Many precipitating factors for asthma exacerbations are known (respiratory tract infections, environmental pollutants, consumption of nonsteroidal anti-inflammatory drugs (NSAIDs), exposure to high pollen densities) and some single outcome variables (e.g. change in daytime symptoms, greater use of rescue $\beta_{2}$-agonist) have some predictive value for exacerbations. Asthma is a heterogeneous disease with many phenotypes, endotypes and underlying patterns of inflammation. Due to a variety of pathogenesis of inflammation in asthma it is difficult to estimate biomarkers that are correlated with a risk of future exacerbations.

Omalizumab is a monoclonal anti-IgE antibody developed for the treatment of severe allergic asthma. The clinical efficacy of omalizumab in reducing the asthma exacerbation rate was described in many clinical trials and "real-life" studies. Treatment of patients with a more homogenous type of inflammation gives hope to find biomarkers that may be a prognostic indicator for patients at a great risk of exacerbations.

As described previously, eosinophils are broadly involved in asthma pathogenesis. Blood eosinophilia has

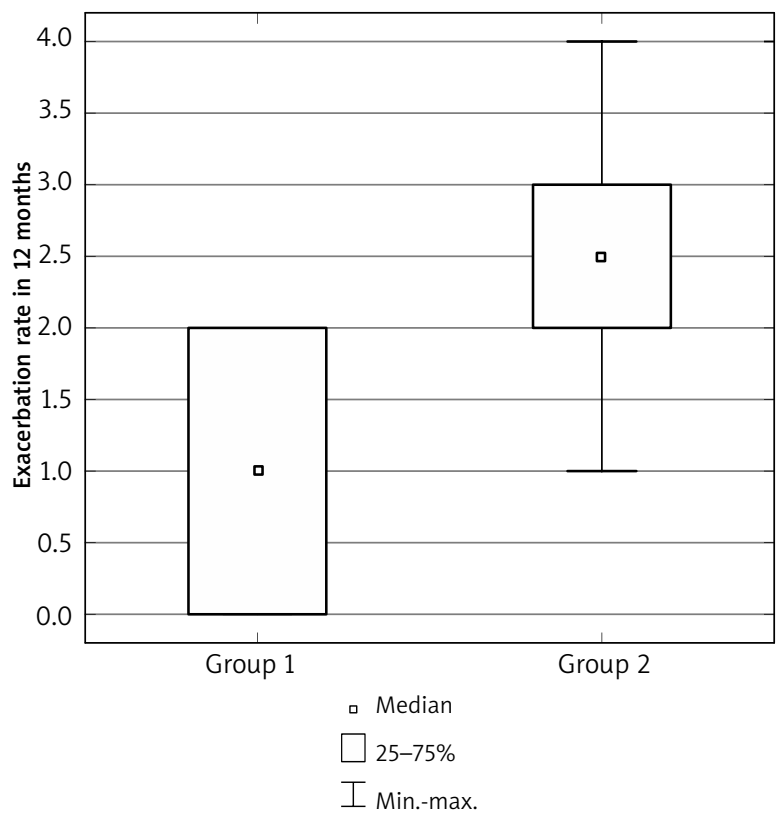

Figure 1. Asthma exacerbation rate during 12 months of anti-lgE therapy

been established as a good marker of inflammation in patients with asthma. Sputum eosinophil counts correlate closely with the risk and severity of exacerbations $[22,23]$. In many studies a decrease in blood eosinophil counts have been found during omalizumab therapy [5]. So far one study has connected asthma exacerbation rate during omalizumab treatment with blood eosinophilia. Busse et al. showed that in patients with an eosinophil count of $300 / \mu$ l or more, omalizumab resulted in $59 \%$ reduction in the rate of exacerbations versus placebo after 28 weeks of treatment. In patients with low eosinophil counts at baseline, anti-lgE therapy did not show effectiveness in asthma exacerbation compared to 


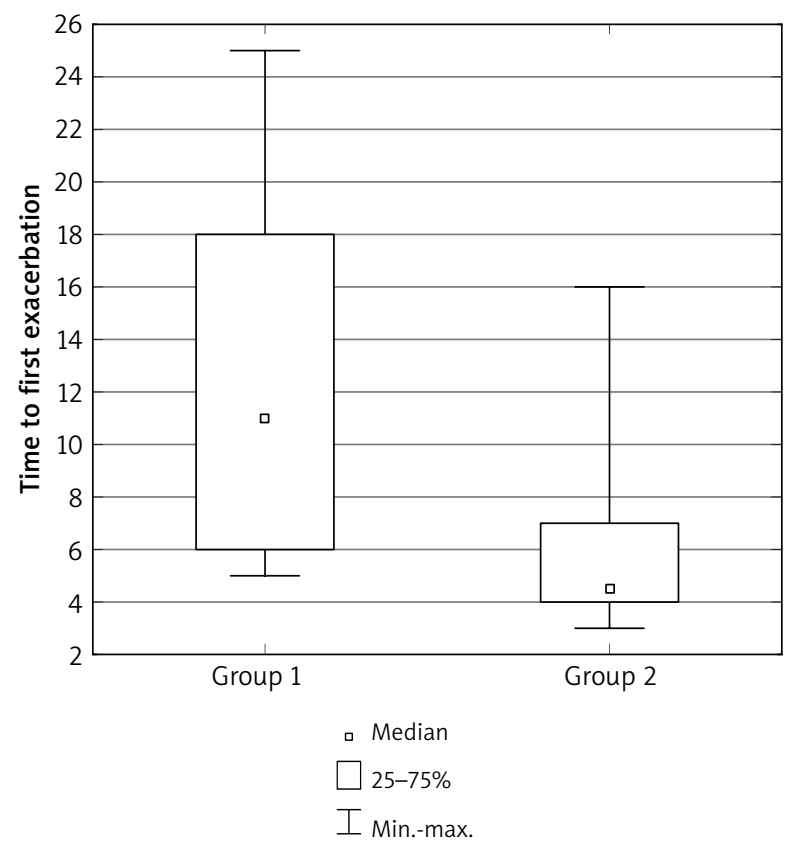

Figure 2. Time to first asthma exacerbation in both groups of studied patients

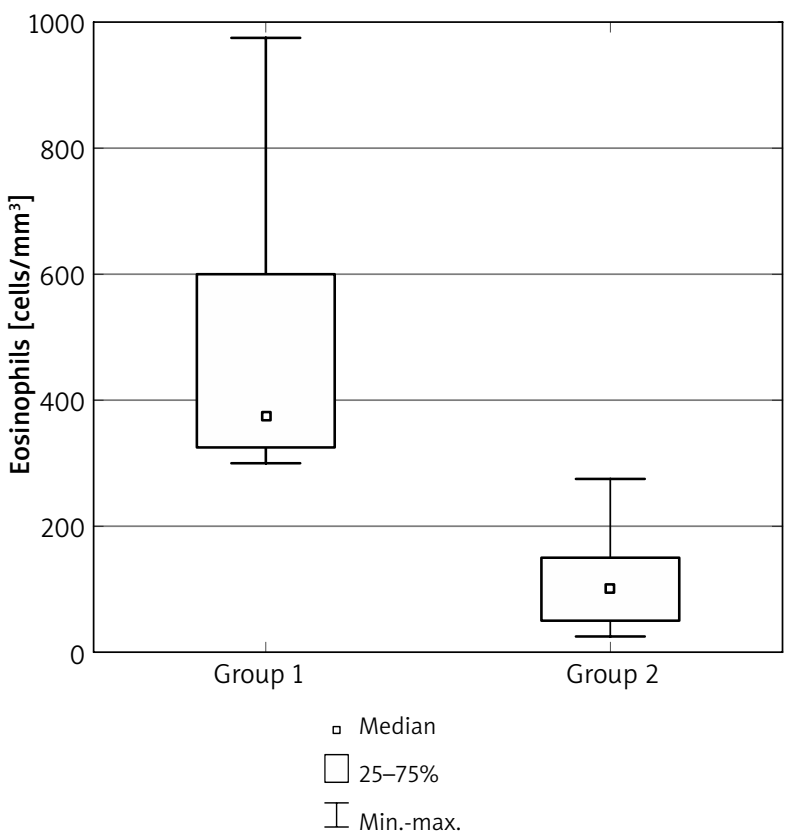

Figure 3. Blood eosinophil count in the studied group of patients

placebo [24]. The authors suggest that high eosinophil counts before the beginning of omalizumab treatment may be a predictive factor of asthma exacerbation.

The above observations encourage us to evaluate usefulness of analysis of changes of blood eosinophilia after 16 weeks of omalizumab therapy as a predictor of asthma exacerbations in the future. Patients with a decrease in blood eosinophils of more than $50 \%$ of the baseline value showed a statistically significant decrease in the exacerbation rate. There was also observed a tendency to prolonged time to first asthma exacerbation, but the differences were not significant.

\section{Conclusions}

Our results showed that a decrease in blood eosinophilia during omalizumab therapy can be a predictor of asthma exacerbations. Evaluation of changes in blood eosinophil counts should be taken in to consideration while estimating response to anti-lgE therapy in patients with severe allergic asthma.

\section{References}

1. Ayres JG, Higgins B, Chilvers ER, et al. Efficacy and tolerability of anti-immunoglobulin $\mathrm{E}$ therapy with omalizumab in patients with poorly controlled (moderate to severe) allergic asthma. Allergy 2004; 59: 701-8.

2. Hanf G, Brachmann I, Kleine-Tebbe J, et al. Omalizumab decreased lgE-release and induced changes in cellular immunity in patients with allergic asthma. Allergy 2006; 61: 1141-4.

3. Zietkowski Z, Skiepko R, Tomasiak-Lozowska MM, Bodzenta-Lukaszyk A. Airway inflammation and eotaxin in exhaled breath condensate of patients with severe persistent allergic asthma during omalizumab therapy. Adv Med Sci 2011; 56: 318-22.

4. Holgate S, Casale T, Wenzel S, et al. The anti-inflammatory effects of omalizumab confirm the central role of IgE in allergic inflammation. J Allergy Clin Immunol 2005; 115: 459-65.

5. Djukanović R, Wilson SJ, Kraft M, et al. Effects of treatment with anti-immunoglobulin E antibody omalizumab on airway inflammation in allergic asthma. Am J Respir Crit Care Med 2004; 170: 583-93.

6. Zietkowski Z, Skiepko R, Tomasiak-Lozowska MM, Bodzenta-Lukaszyk A. Anti-lgE therapy with omalizumab decreases endothelin-1 in exhaled breath condensate of patients with severe persistent allergic asthma. Respiration 2010; 80: 534-42.

7. Fahy JV, Fleming HE, Wong HH, et al. The effect of an anti-lgE monoclonal antibody on the early- and late-phase responses to allergen inhalation in asthmatic subjects. Am J Respir Crit Care Med 1997; 155: 1828-34.

8. Holgate ST, Chuchalin AG, Hébert J, et al. Omalizumab 011 International Study Group. Efficacy and safety of a recombinant anti-immunoglobulin E antibody (omalizumab) in severe allergic asthma. Clin Exp Allergy 2004; 34: 632-8.

9. Humbert M, Beasley R, Ayres J, et al. Benefits of omalizumab as add-on therapy in patients with severe persistent asthma who are inadequately controlled despite best available therapy (GINA 2002 step 4 treatment): INNOVATE. Allergy 2005; 60: 309-16.

10. Fritscher L, Chapman KR. Omalizumab for asthma: pharmacology and clinical profile. Expert Rev Respir Med 2009; 3: 119-27.

11. Bousquet J, Cabrera P, Berkman N, et al. The effect of treatment with omalizumab, an anti-IgE antibody, on asthma exacerbations and emergency medical visits in patients with severe persistent asthma. Allergy 2005; 60: 302-8. 
12. Milgrom H, Fick RB Jr, Su JQ, et al. Treatment of allergic asthma with monoclonal anti-IgE antibody. N Engl J Med 1999; 341: 1966-73.

13. Solèr M, Matz J, Townley R, et al. The anti-lgE antibody omalizumab reduces exacerbations and steroid requirement in allergic asthmatics. Eur Respir J 2001; 18: 254-61.

14. Busse W, Corren J, Lanier BQ, et al. Omalizumab, anti-IgE recombinant humanized monoclonal antibody, for the treatment of severe allergic asthma. J Allergy Clin Immunol 2001; 108: 184-90.

15. Kay AB, Frew AJ, Moqbel R, et al. The activated eosinophil in allergy and asthma. Prog Clin Biol Res 1989; 297: 183-96.

16. Massanari M, Holgate ST, Busse WW, et al. Effect of omalizumab on peripheral blood eosinophilia in allergic asthma. Respir Med 2010; 104: 188-96.

17. Green RH, Brightling CE, McKenna S, et al. Asthma exacerbations and sputum eosinophil counts: a randomised controlled trial. Lancet 2002; 360: 1715-21.

18. Global Initiative for Asthma: Global strategy for asthma management and prevention: NHLBI/WHO Report 2006, publication 02-3569.

19. Hochhaus G, Brookman L, Fox H, et al. Pharmacodynamics of omalizumab: implications for optimized dosing strategies and clinical efficacy in the treatment of allergic asthma. Curr Med Res Opin 2003; 19: 491-8.

20. Recommendations for standardized procedures for the online and off-line measurement of exhaled lower respiratory nitric oxide and nasal nitric oxide in adults and children 1999. This official statement of the American Thoracic Society was adopted by the ATS Board of Directors, July 1999. Am J Respir Crit Care Med 1999; 160: 2104-17.

21. American Thoracic Society. Lung function testing: selection of reference values and interpretative strategies. Am Rev Respir Dis 1991; 144: 1202-18.

22. Petsky HL, Kynaston JA, Turner C, et al. Tailored interventions based on sputum eosinophils versus clinical symptoms for asthma in children and adults. Cochrane Database Syst Rev 2007; 2: CD005603.

23. Green RH, Brightling CE, McKenna S, et al. Asthma exacerbations and sputum eosinophil counts: a randomised controlled trial. Lancet 2002; 360: 1715-21.

24. Busse W, Spector S, Rosén K, et al. High eosinophil count: a potential biomarker for assessing successful omalizumab treatment effects. J Allergy Clin Immunol 2013; 132: 485-6. 